\title{
Thermoplastic polyurethane coatings made with mixtures of polyethers of different molecular weights with pressure sensitive adhesion property
}

\author{
Mónica Fuensanta, José Miguel Martin-Martínez* \\ Adhesion and Adhesives Laboratory, University of Alicante, 03080 Alicante, Spain
}

\section{A R T ICLE INFO}

\section{Keywords:}

Thermoplastic polyurethane coating

Pressure sensitive adhesion property

Rheology

Tack

$180^{\circ}$ peel adhesion

\begin{abstract}
A B S T R A C T
Thermoplastic polyurethane (PU) coatings with pressure sensitive adhesion property were synthetized by reacting 4,4'-diphenylmethane diisocyanate (MDI) with 1,4-butanediol and mixtures of polypropylene glycols (PPGs) of different molecular weights (1000 and $2000 \mathrm{Da}$ ). Good tack at $10-37^{\circ} \mathrm{C}$ was obtained in PU coatings prepared with PPG2000 + PPG1000 mixtures containing $50 \mathrm{wt} \%$ or more PPG2000. The pressure sensitive adhesion properties of the PU coatings were related to their minor content of bonded urethane groups and important degree of phase separation. Furthermore, these PU coatings followed Dahlquists criterium, they showed low glass transition temperatures, high tack, and low $180^{\circ}$ peel strength. Therefore, the PU coatings had potential as pressure sensitive adhesives. Finally, PU coating made with PPG of molecular weight 1000 Da did not show pressure sensitive adhesion property.
\end{abstract}

\section{Introduction}

Pressure sensitive adhesives (PSAs) are commonly used in the manufacture of tapes and labels for several applications such as memory notes, patches, removable films, etc [1]. Several polymers are used for manufacturing PSAs such as synthetic rubbers, acrylics, silicones, polyesters and polyurethanes [2]. Because of environmental regulations, organic solvents must be removed from PSA formulations and, therefore, waterborne PSAs [3,4], hot-melt PSAs [5], ultraviolent curable PSAs [6] and electron beam curable PSAs [7] have been developed.

PSAs are characterized by forming immediate adhesion joints with several substrates under application of light pressure. Because of the performance of PSAs is related to dual viscoelastic behavior, i.e. viscous component (to wet the substrate for good contact during bonding) and elastic component (to withstand shear stresses and peel forces during debonding), their viscoelastic properties must be carefully designed. Copolymers with segmented structure are commonly used for controlling the viscoelastic properties of PSAs because of the hard phase imparts the elastic properties and the soft phase imparts the viscous properties. In this sense, the thermoplastic polyurethanes can be good potential versatile polymers for manufacturing PSAs. On one side, the thermoplastic polyurethanes have tunable structure-property relationships which derive from the existence of thermodynamically incompatible hard and soft segments [8]. The soft "flexible" segments are constituted by high molecular weight polyols providing flexibility to the polymer backbone, and the hard "rigid" segments due to the diisocyanate and low molecular weight diol or diamine (chain extender) are polar and impart the mechanical properties.

It is well known that the pressure sensitive adhesion property is not typical of the polyurethanes because of their low tack and low peel adhesive strength. Some previous patents $[9,10]$ proposed the addition of tackifiers or the compounding with other polymers for adjusting the glass transition temperature and decreasing the elastic modulus at room temperature in polyurethanes intended for PSAs (PU PSAs). Unfortunately, these PU PSAs developed strong peel strength with the time causing damage of the substrate upon removal and, furthermore, the tackifier in the formulation migrates to the substrate surface $[11,12]$. In a different approach, Nakamura et al. [13] have recently demonstrated that the addition of crosslinking agent (trimethylolpropane/ toluene-2,4-diisocyanate) increased the peel strength of polyurethane and exhibited frequency dependence of the storage modulus during dynamic viscoelastic measurements. Additionally, the

\footnotetext{
Corresponding author.

Email address: jm.martin@ua.es (J.M. Martin-Martínez)
} 
rolling tack of the cross-linked PU PSAs did not depend on the rolling rate.

Grafting is another strategy used for obtaining PU PSAs with adequate performance. Baron et al. [14] reported the synthesis of graft polyurethanes by using the prepolymer method, and they found that the hard to soft segments ratio and the existence of crystallizable fragments could improve the adhesion properties of PU PSAs. On the other hand, polypropylene glycols (PPGs) with different molecular weights and hydroxyl-terminated polybutadiene (HTPB) polyols were reacted with aliphatic diisocyanates to obtain grafted PU PSAs [15]. It was found that the increase of the molecular weight of PPG, increased the storage modulus of the polyurethane, whereas the increase of the polybutadiene content increased the tack. Furthermore, high complex modulus was obtained anticipating high shear resistance.

Another recent strategy for obtaining PU PSAs is the use of waterborne hybrid polyurethanes for producing coatings with pressure sensitive adhesion property. Lopez et al. [16] used free radical miniemulsion polymerization for the synthesis of acrylic/polyurethane hybrids which microstructure was modified by adding different diols as chain extenders. The use of bisphenol A as chain extender led to adhesives with greater shear resistance due to higher crosslinking density and acceptable viscoelasticity. In later publication, the same authors found that the increase of the chain transfer agent concentration increased the tack of the hybrid polyurethanes because of lower gel content and greater chain mobility [17]. A different research in miniemulsion polymerization of polyurethane/acrylic hybrid polymers was carried out by Degrandi-Contraires et al. $[18,19]$ in which grafted polyurethane prepolymer onto acrylic backbone through a reactive monomer was prepared.

In this study, different approach for preparing PU PSAs is proposed. Thermoplastic polyurethane (PU) coatings were synthetized by designing their structure in such a way that tack at room temperature can be obtained. Thermoplastic PU coatings were prepared by using the prepolymer method and the reactants were methylenediphenyl diisocyanate, 1,4-butanediol, and mixtures of polypropylene glycols of different molecular weights (1000 and $2000 \mathrm{Da})$. We propose that the pressure sensitive adhesion property of the thermoplastic PU coatings can be imparted by adequate design of the segmented structure of the polyurethane, i.e., the control of the degree of phase separation of the hard and soft segments.

\section{Experimental}

\subsection{Materials}

4,4'-Diphenylmethane diisocyanate (MDI) flakes - Desmodur ${ }^{\circledR}$ 44MC-supplied by Covestro (Leverkusen, Germany) was used as aromatic isocyanate. Polypropylene glycols with molecular weights of 2000 Da (PPG2000)-Alcupol ${ }^{\circledR}$ D2021 supplied by Repsol (Madrid, Spain)-and 1000 Da (PPG1000)-Alcupol ${ }^{\circledR}$ D1011 supplied by Repsol (Madrid, Spain) were used as polyols. 1,4-butanediol (BD) supplied by Sigma Aldrich Co. LLC (St. Louis, MO, USA) was used as chain extender. Dibutyl tin dilaurate (DBTDL) supplied by Sigma Aldrich Co. LLC (St. Louis, MO, USA) was used as catalyst. Before use, the polyols were melted and dried at $80{ }^{\circ} \mathrm{C}$ under reduced pressure (300 mbar) for $2 \mathrm{~h}$.

\subsection{Synthesis of the thermoplastic polyurethanes}

Thermoplastic polyurethanes were synthesized by using the prepolymer method. Polyurethane prepolymer was synthesized in $500 \mathrm{~cm}^{3}$ four-neck round-bottom glass reactor under nitrogen atmosphere by reacting melted MDI with dried PPG or mixtures of PPGs at $80^{\circ} \mathrm{C}$. The mixture was stirred with anchor shaped stirrer at $250 \mathrm{rpm}$ and $80^{\circ} \mathrm{C}$ during $30 \mathrm{~min}$ in Heidolph overhead stirrer RZR-2000 (Kelheim, Germany). Then, $0.04 \mathrm{mmol}$ of catalyst (DBTDL) was added and the stirring was carried out at $80{ }^{\circ} \mathrm{C}$ and $80 \mathrm{rpm}$ during $2 \mathrm{~h}$. The amount of free NCO in the prepolymer was monitored by dibutylamine titration. Once the desired free NCO content was obtained, the chain extender (BD) was added and the mixture was stirred at $80 \mathrm{rpm}$ and $80^{\circ} \mathrm{C}$ during $5 \mathrm{~min}$. The NCO/OH ratio used was 1.10 . Fig. 1 shows the scheme of the synthesis of the thermoplastic polyurethanes.

The nomenclature and composition of PU PSAs are shown in Table 1. In general, the hard segment content of the polyurethanes was low and it was varied by changing the molecular weight of the PPG and the composition of the mixtures of PPGs. As expected, the higher hard segment content corresponds to the polyurethane made with PPG1000 and the lowest one corresponds to the one made with PPG2000. Intermediate hard segment contents were obtained in the polyurethanes made with mixtures of PPGs.

\subsection{Experimental techniques}

\subsubsection{Attenuated total reflection infrared spectroscopy (ATR-IR)}

ATR-IR spectra of the polyols and thermoplastic polyurethanes were obtained in Tensor 27 FT-IR spectrometer (Bruker Optik GmbH, Erlinger, Germany) by using Golden Gate single reflection diamond ATR accessory at $25{ }^{\circ} \mathrm{C}$. In absorbance mode, 64 scans were recorded and averaged with resolution of $4 \mathrm{~cm}^{-1}$ in the wavenumber range of $4000-400 \mathrm{~cm}^{-1}$.

\subsubsection{Differential scanning calorimetry (DSC)}

The structure and thermal properties of the polyols and the thermoplastic polyurethanes were determined in DSC Q100 calorimeter (TA Instruments, New Castle, DE, USA). Hermetically sealed aluminum pans containing $10-15 \mathrm{mg}$ of sample were prepared. All samples were heated from -80 to $150^{\circ} \mathrm{C}$ under nitrogen atmosphere (flow rate: $50 \mathrm{~mL} \mathrm{~min}^{-1}$ ) by using a heating rate of $10{ }^{\circ} \mathrm{C} \mathrm{min}^{-1}$. The first DSC heating run was carried out to remove the thermal history of the polyurethanes and the glass transition temperature $\left(T_{\mathrm{g}}\right)$ was obtained from the second DSC heating run.

\subsubsection{Thermal gravimetric analysis (TGA)}

The thermal degradation of the thermoplastic polyurethanes was assessed in TGA Q500 equipment (TA Instruments, New Castle, USA) under nitrogen atmosphere $\left(50 \mathrm{~mL} \mathrm{~min}^{-1}\right) .5-10 \mathrm{mg}$ of thermoplastic polyurethanes were placed in platinum crucible and, then, heated from 50 to $800{ }^{\circ} \mathrm{C}$ by using a heating rate of $10^{\circ} \mathrm{C} \mathrm{min}^{-1}$.

\subsection{Plate-plate rheology}

The rheological and viscoelastic properties of the thermoplastic polyurethanes were determined in DHR-2 rheometer (TA Instruments, New Castle, DE, USA) in parallel plate-plate geometry. The gap selected was $0.40 \mathrm{~mm}$, and $20 \mathrm{~mm}$ diameter stainless steel parallel plates were used. The linear viscoelastic region (LVE) of the thermoplastic polyurethanes was established by stress amplitude sweep experiments at $25{ }^{\circ} \mathrm{C}$ and frequency of $1 \mathrm{~Hz}$ by using a range of shear strains from 0.01 to $100 \%$. In the region of linear viscoelasticity, the storage ( $\left.G^{\prime}\right)$ and loss (G”) moduli of PU PSAs were measured at $25{ }^{\circ} \mathrm{C}$ by frequency sweep mode experiments, a strain amplitude of $2.5 \%$ in the angular frequency range from 0.01 to $100 \mathrm{rad} \mathrm{s}^{-1}$ was used.

Furthermore, the viscoelastic properties of PU PSAs were measured by temperature sweep mode experiments from -20 to $120^{\circ} \mathrm{C}$, a frequency of $1 \mathrm{~Hz}$ and a heating rate of $5^{\circ} \mathrm{C} \mathrm{min}-1$ were used. 


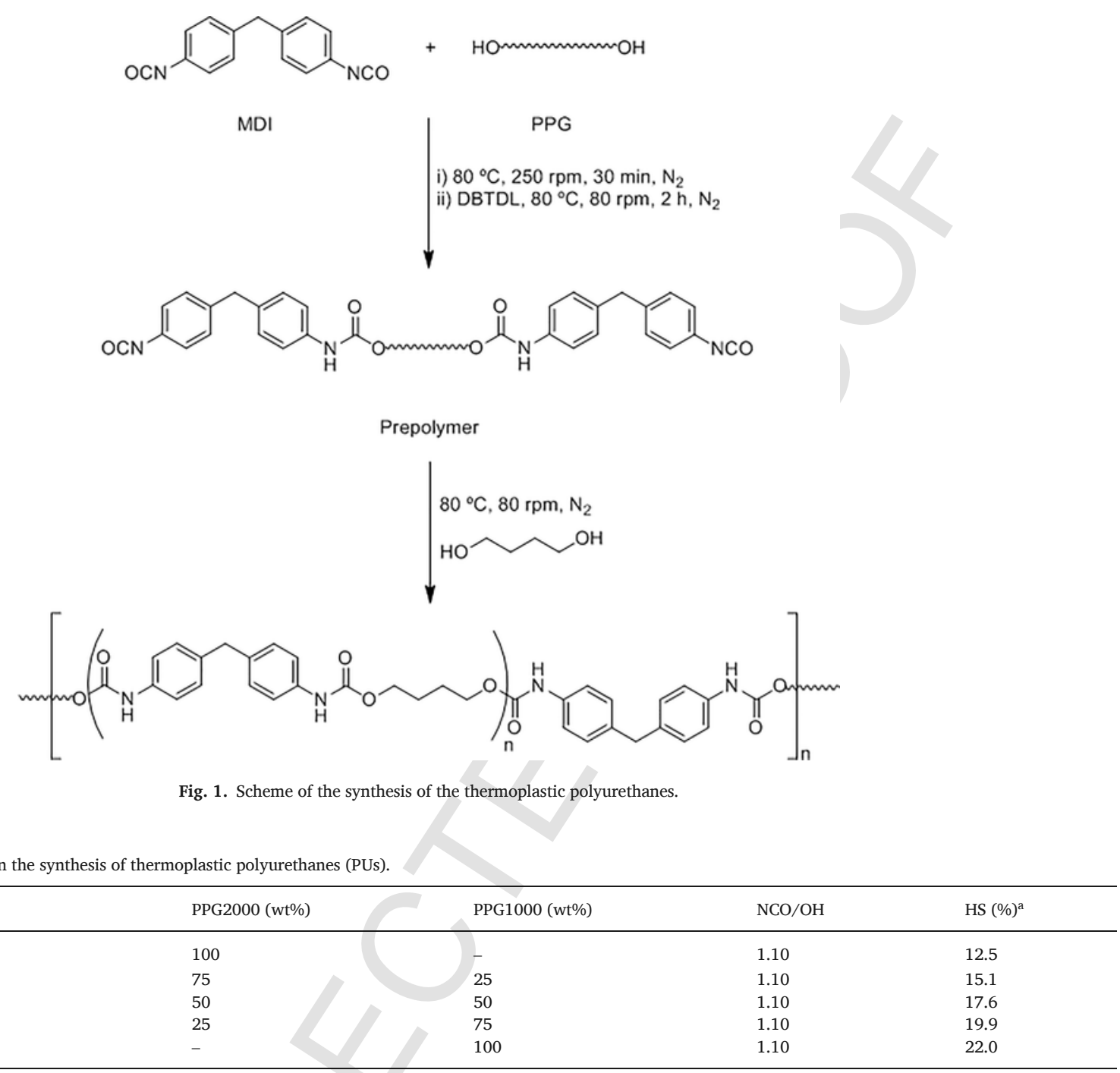

Table 1

Nomenclature and reactants used in the synthesis of thermoplastic polyurethanes (PUs).

\begin{tabular}{|c|c|c|c|c|}
\hline PU & PPG2000 (wt\%) & PPG1000 (wt\%) & $\mathrm{NCO} / \mathrm{OH}$ & HS $(\%)^{\mathrm{a}}$ \\
\hline PU-PPG2000 & 100 & - & 1.10 & 12.5 \\
\hline PU-PPG2000(75)/PPG1000(25) & 75 & 25 & 1.10 & 15.1 \\
\hline PU-PPG2000(50)/PPG1000(50) & 50 & 50 & 1.10 & 17.6 \\
\hline PU-PPG2000(25)/PPG1000(75) & 25 & 75 & 1.10 & 19.9 \\
\hline PU-PPG1000 & - & 100 & 1.10 & 22.0 \\
\hline
\end{tabular}

a Hard segment content was calculated according to the following equation: HS $=100 \mathrm{x}$ [weight (MDI) + weight (BD)]/[total weight].

\subsection{Probe tack}

The probe tack of the thermoplastic PU coatings was measured at 10, 25 and $37^{\circ} \mathrm{C}$ in TA.XT2i Texture Analyzer (Stable Micro Systems, Surrey, UK). PU coatings of 40-80 $\mu \mathrm{m}$ thick were placed on rectangular stainless steel 304 plates of dimensions $7 \times 7 \times 0.01 \mathrm{~cm}$. Flat end cylindrical stainless steel probe of $3 \mathrm{~mm}$ diameter was used. The probe was brought into contact with the PU coating for $1 \mathrm{~s}$ under a load of $5 \mathrm{~N}$. Then, the probe was pulled out at a constant speed of $1 \mathrm{~mm} \mathrm{~s}^{-1}$. For each PU coating, five replicates were carried out and averaged.

\section{6. $180^{\circ}$ peel strength}

Adhesion properties of thermoplastic PU coatings were determined by $180^{\circ}$ peel tests of aluminum 5754/PU coating/polyethylene terephthalate (PET) film joints. Around $80 \mu \mathrm{m}$ thick PU coating was placed on PET film of dimensions $30 \times 150 \times 0.50 \mathrm{~mm}$. Then, the aluminum 5754 plate of dimensions $30 \times 150 \times 2 \mathrm{~mm}$ was placed on top and a pressure of $0.8 \mathrm{MPa}$ for $10 \mathrm{~s}$ was applied. One hour after joint formation, the $180^{\circ}$ peel test was carried out in Instron 4411 universal testing machine (Instron Ltd., Buckinghamshire, UK) by using a pulling rate of $152 \mathrm{~mm} \mathrm{~min}^{-1}$. A length of $30 \mathrm{~cm}$ in the joint was peeled, and the initial values of $180^{\circ}$ peel strength were discarded. Five replicates were tested and averaged for each adhesive joint.

\section{Results and discussion}

\subsection{Structural characterization of the thermoplastic PUs}

Fig. 2 shows the chemical structure and the ATR-IR spectra of PPG polyols of different molecular weights. As expected, the ATR-IR spectra of both polyols are similar and they show the stretching of $\mathrm{O}-\mathrm{H}$ group at 3455-3476 $\mathrm{cm}^{-1}$, the asymmetric stretching of $\mathrm{C}-\mathrm{O}-\mathrm{C}$ group at $1094-1089 \mathrm{~cm}^{-1}$, the stretching $\mathrm{CH}_{3}$ band at 2970 and $1372 \mathrm{~cm}^{-1}$, and the methylene bands at 2868, 1454, 927 and $837 \mathrm{~cm}^{-1}$.

The ATR-IR spectra of the thermoplastic PUs made with PPG1000, PPG2000 and PPG2000 + PPG1000 mixtures are given in Fig. 3; the ATR-IR spectra were normalized with respect to the intensity of the $\mathrm{N}$ $-\mathrm{H}$ stretching bands that is similar in all spectra. All ATR-IR spectra show the same absorption bands: $\mathrm{N}-\mathrm{H}$ stretching of urethane group at 3513 and $3302 \mathrm{~cm}^{-1}, \mathrm{C}-\mathrm{H}$ bands of PPG polyol at $2970-2868 \mathrm{~cm}^{-1}$ and 1453 and $1373 \mathrm{~cm}^{-1}$, and $\mathrm{C}-\mathrm{O}-\mathrm{C}$ bands of PPG polyol at $1090-1017 \mathrm{~cm}^{-1}$. Free urethane end carbonyl attached to $\mathrm{N}-\mathrm{H}$ hydrogen bonded to ether groups are identified by the $\mathrm{C}=\mathrm{O}$ stretching band at $1728 \mathrm{~cm}^{-1}$ and by the absorption bands of amide II 


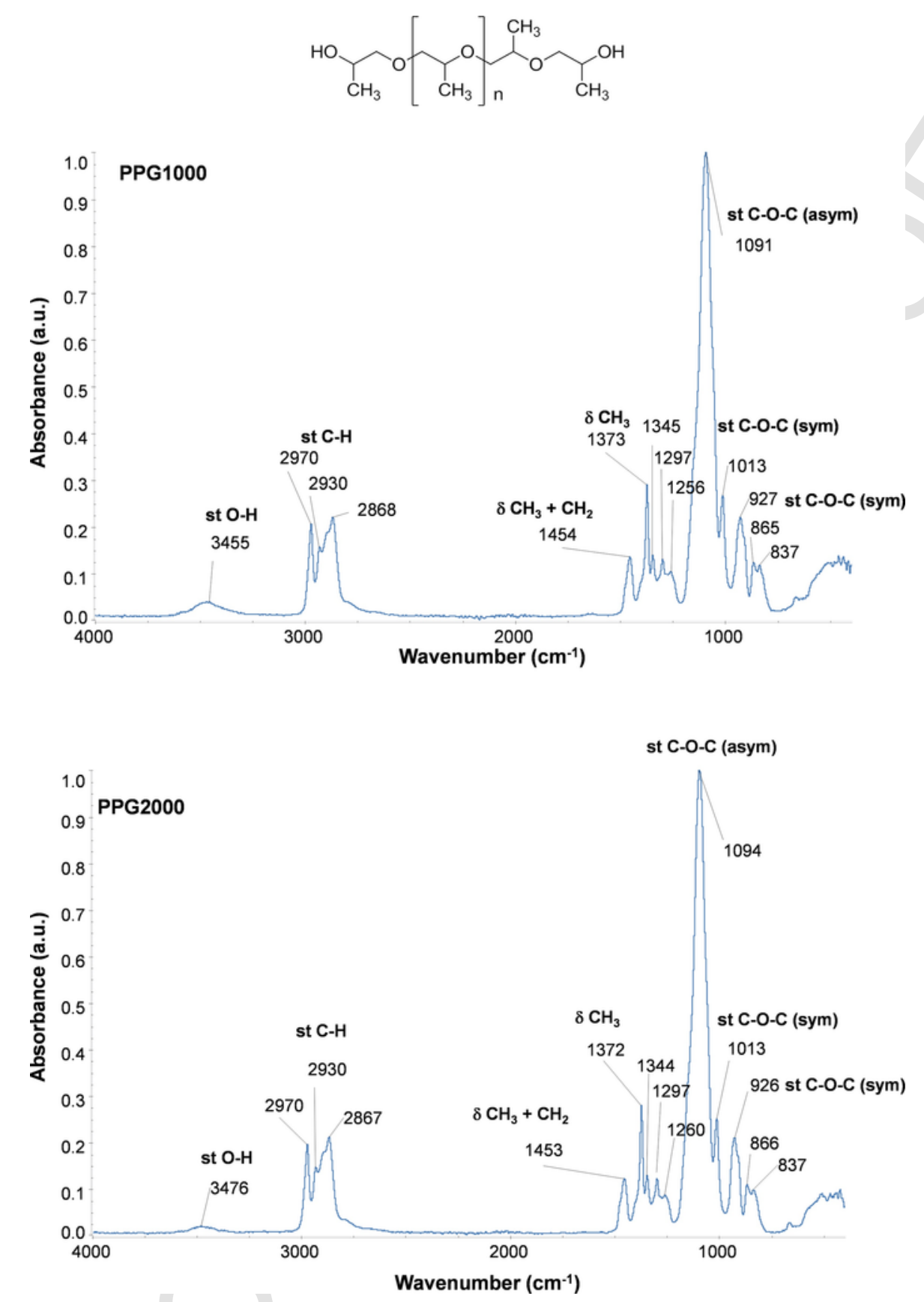

Fig. 2. Chemical structure of PPG and ATR-IR spectra of PPG1000 and PPG2000.

and amide III at 1534 and $1223 \mathrm{~cm}^{-1}$ respectively. The characteristic bands of the aromatic ring of the isocyanate appear at 1412, 817 and $512 \mathrm{~cm}^{-1}$ [20].

The carbonyl bands in the ATR-IR spectra of all polyurethanes are not symmetrical, pointing to the existence of free and associated urethane groups. The carbonyl absorption bands in the IR spectra of poly(ether urethane)s has been assigned to $1738 \mathrm{~cm}^{-1}$ for the free urethane group (not bonded by hydrogen bonding) and to $1728 \mathrm{~cm}^{-1}$ for the free urethane end carbonyl attached to $\mathrm{N}-\mathrm{H}$ hydrogen bonded to group [21]. Furthermore, according to the literature [22], the absorption band at $1708 \mathrm{~cm}^{-1}$ was assigned to the stretching of hydrogen-bonded carbonyl group of urethane. In order to analyze the relative contribution of free and associated urethane groups in the thermoplastic PUs, the curve fitting of the carbonyl region of the ATR-IR spectra was carried out; Gaussian function was used and the free urethane end carbonyl attached to $\mathrm{N}-\mathrm{H}$ hydrogen bonded to ether group was fitted at $1728 \mathrm{~cm}^{-1}$ and bonded urethane carbonyl was fitted at $1708 \mathrm{~cm}^{-1}$.

Fig. 4a shows the variation of the percentages of free and bonded urethanes of the thermoplastic PUs as a function of their PPG1000 content. Free urethane is dominant in the polyurethanes containing $50 \mathrm{wt} \%$ or less PPG1000; however, bonded urethane becomes significant in the polyurethanes made with 75 wt\% PPG1000. Furthermore, the increase of the amount of PPG2000 in the polyurethanes increases the percentage of free urethane and decreases the one of the bonded urethane. The higher fraction of associated urethane groups indicates lower degree of phase separation between the hard and soft domains.

The degree of phase separation of thermoplastics PUs is governed by their composition and $\mathrm{NCO} / \mathrm{OH}$ ratio [8]. In this study, the different structures of PUs can be ascribed to changes in the degree of phase sep- 


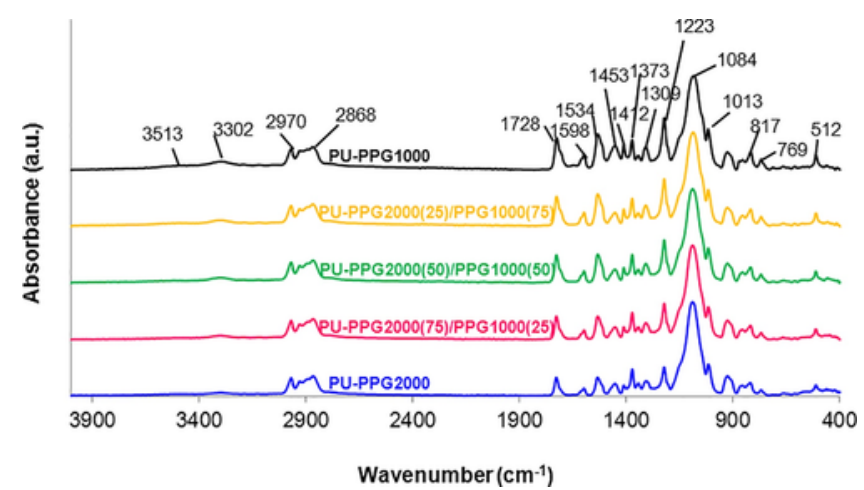

Fig. 3. ATR-IR spectra of the thermoplastic PUs made with PPG1000, PPG2000 and PPG2000 + PPG1000 mixtures.

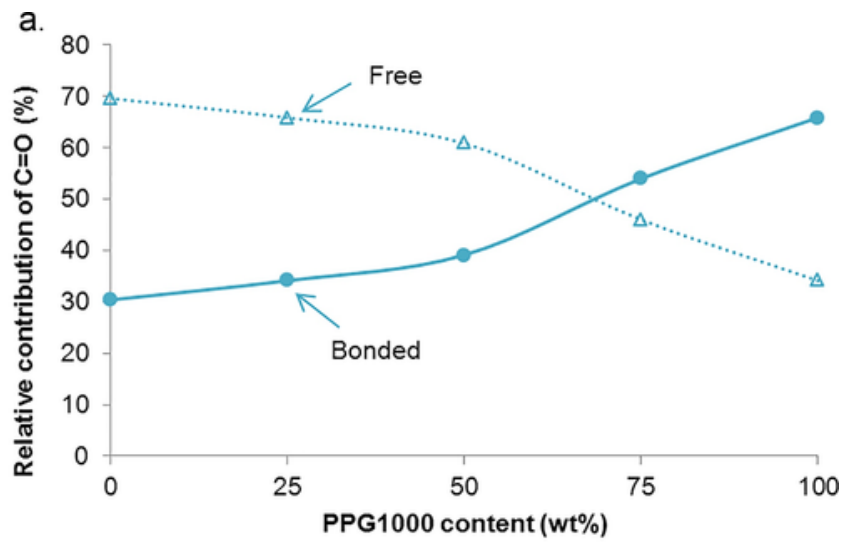

b.

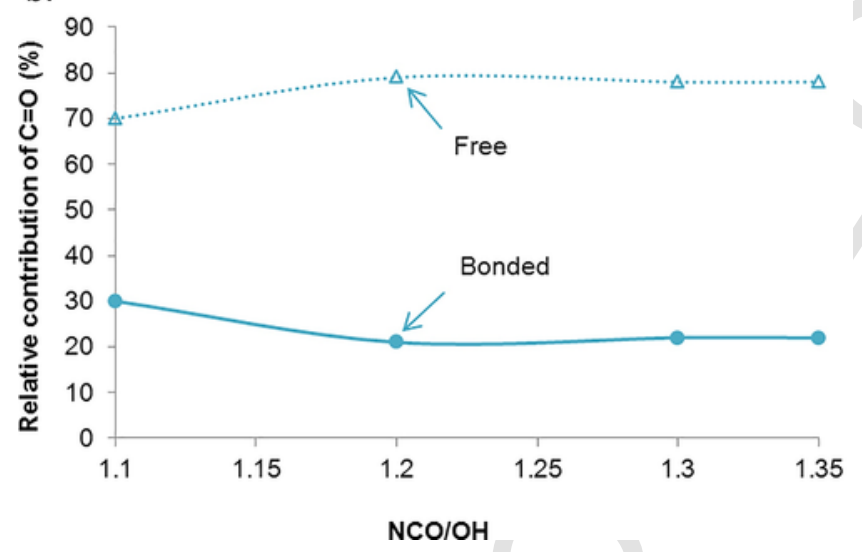

Fig. 4. (a) Relative contributions of free and bonded urethane groups in the thermoplastic PUs as a function of their PPG1000 content. (b) Rbelative contributions of free and bonded urethane groups in the thermoplastic PUs made with PPG2000 as a function of their NCO/ $\mathrm{OH}$ content.

aration due to their different content of polyols with different molecular weights. However, the different contents of PPG1000 and PPG2000 also produced a change in the hard segment contents of the polyurethanes (Table 1). For discriminating the influence of the polyol amount and the hard segment content on the structure of the thermoplastic polyurethanes, three polyurethanes were synthesized with PPG2000 only and the $\mathrm{NCO} / \mathrm{OH}$ ratio was varied between 1.10 and 1.35 , i.e., the hard segment content is similar (12.5-13.0\%) but the amount of polyol is different. From the ATR-IR spectra of the polyurethanes, the contents of free and associated urethane are obtained. According to Fig. $4 b$, the percentage of free urethane is higher than the one of bonded one, and similar percentages are obtained in all polyurethanes, irrespective of their $\mathrm{NCO} / \mathrm{OH}$ ratio and their polyol content. Therefore, in this study, the structure of thermoplastic PUs is more influenced by their hard segments content than by the amount of polyols.

The structure of the thermoplastic PUs was also analyzed by DSC. The DSC thermograms of PPG polyols show one glass transition only at $-69^{\circ} \mathrm{C}$, irrespective of their molecular weight. DSC thermograms of the polyurethanes are given in Fig. 5 and they show only the glass transition of the soft segments. The glass transition temperatures $\left(\mathrm{T}_{\mathrm{g}} \mathrm{s}\right)$ of the PUs increase by increasing their PPG1000 content and they are higher than the $\mathrm{T}_{\mathrm{g}} \mathrm{s}$ of the polyols. Because of the increase in PPG1000 causes an increase in the content of the hard segments (or a decrease in the content of the soft segments) in the thermoplastic PUs (Table 1), an increase of $\mathrm{T}_{\mathrm{g}}$ can be expected.

The thermal degradation of the thermoplastic PUs was analyzed by TGA. Fig. 6 shows the TGA thermograms of the polyols. PPG2000 starts to decompose thermally earlier than PPG1000, and both polyols decompose at similar temperature $\left(350-351^{\circ} \mathrm{C}\right)$. TGA thermograms of the thermoplastic PUs are given in Fig. 7a. The starting of the thermal decomposition of PU-PPG2000 is produced at higher temperature than in the rest of the polyurethanes. Table 2a shows the temperatures at which $5\left(\mathrm{~T}_{5 \%}\right)$ and $50\left(\mathrm{~T}_{50 \%}\right)$ wt $\%$ are lost, and the temperature of maximum decomposition $\left(\mathrm{T}_{\max }\right.$ ) of the thermoplastic PUs. The highest values correspond to PU-PPG2000 and, interestingly, the lowest ones correspond to PU-PPG2000(75)/PPG1000(25), instead to PU-PPG1000. Furthermore, $\mathrm{T}_{5 \%}$ values of the thermoplastic PUs made with PPG2000 + PPG1000 mixtures are lower than the ones made with one polyol only. Therefore, the structures of the thermoplastic PUs are affected by their content in polyols of different molecular weights. All polyurethanes show two main thermal decompositions that can be more clearly distinguished in the derivative TGA plots of Fig. 7b. The maximum temperature and weight loss of the two thermal decompositions of the polyurethanes are given in Table $2 \mathrm{~b}$. The thermal decomposition at $310-329^{\circ} \mathrm{C}$ corresponds to the breakdown of the urethane hard domains and the one at $359-368^{\circ} \mathrm{C}$ corresponds to the one of the polyol soft domains [23]. The thermal decomposition of the soft domains of the polyurethanes is produced at higher temperature than for the polyols. Because of the structure of the thermoplastic polyurethanes is dominated by the soft segments, their main weight losses are produced at $359-368^{\circ} \mathrm{C}$. As compared to the other thermoplastic PUs, PU-PPG2000 shows clearer distinction between the thermal decompositions of the soft and hard domains because of higher degree of phase separation. However, the addition of $25 \mathrm{wt} \%$ PPG1000 causes a noticeable decrease of the degree of phase separation evidenced by the shoulder at $311^{\circ} \mathrm{C}$ (Fig. 7b) and similar weight losses of the hard and soft domains than for PU-PPG2000 are obtained; furthermore, for PU-PPG2000(75)/PPG1000(25), the values of $\mathrm{T}_{5 \%}, \mathrm{~T}_{50 \%}$ and $\mathrm{T}_{\max }$ are the lowest among all PUs. On the other hand, the weight

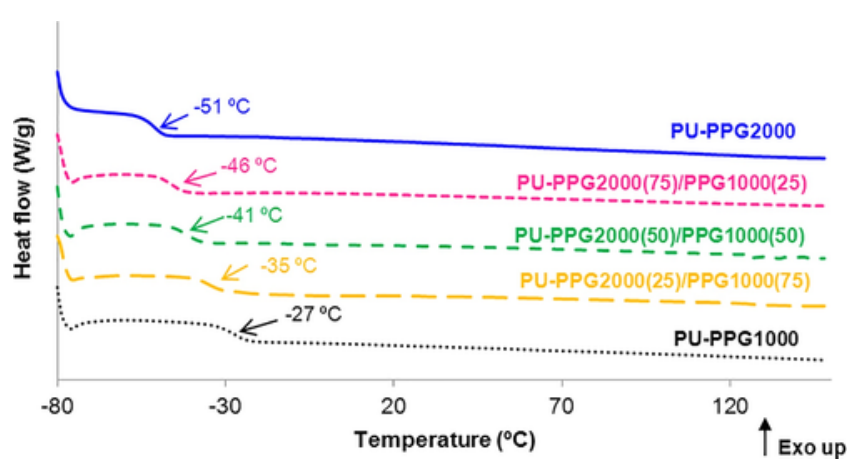

Fig. 5. DSC thermograms of the thermoplastic PUs prepared with PPG1000, PPG2000 and PPG2000 + PPG1000 mixtures. 

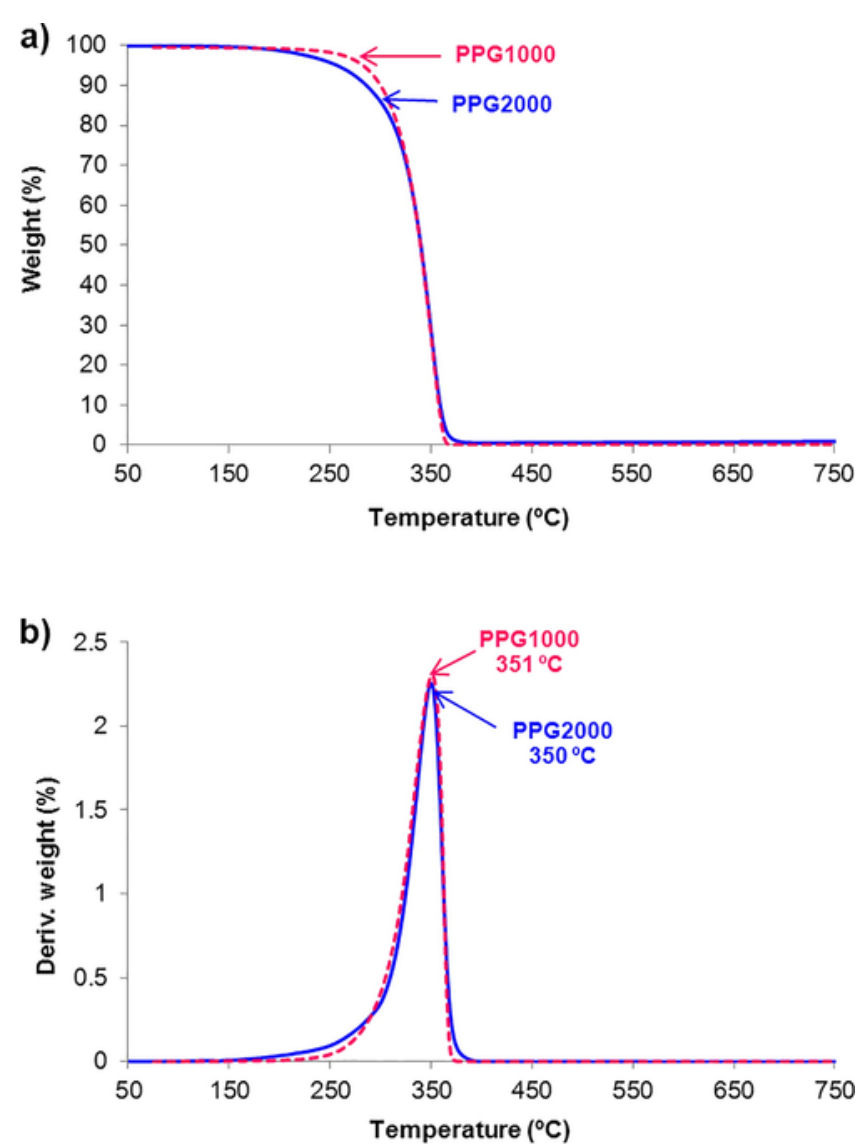

Fig. 6. Variation of (a) the weight and (b) the derivative of the weight of the polyols (PPG2000 and PPG1000) as a function of the temperature.

losses due to the hard domains increase and the ones of the soft domains decrease by increasing the PPG1000 content of the thermoplastic PUs. Whereas, the temperature at which the soft domains decompose is similar in all polyurethanes [PU-PPG2000(75)/PPG1000(25) is an exception], the temperature of thermal decompositions of the hard domains increases from $310{ }^{\circ} \mathrm{C}$ in PU-PPG2000 to $326{ }^{\circ} \mathrm{C}$ in PU-PPG2000(50)/ PPG1000(50), indicating the existence of stronger interactions; however, similar temperatures of the thermal decompositions of the hard domains are found in the polyurethanes made with $50 \mathrm{wt} \%$ or more PPG1000.

\subsection{Rheological and viscoelastic properties of the thermoplastic PUs}

Amplitude sweep experiments were carried out for obtaining the region of linear viscoelasticity in the thermoplastic PUs. Fig. 8 shows the variation of the storage and loss moduli as a function of the strain at $25{ }^{\circ} \mathrm{C}$ for the polyurethanes, and they show similar values of moduli for strain values between 0.01 and $5 \%$; on the other hand, the region
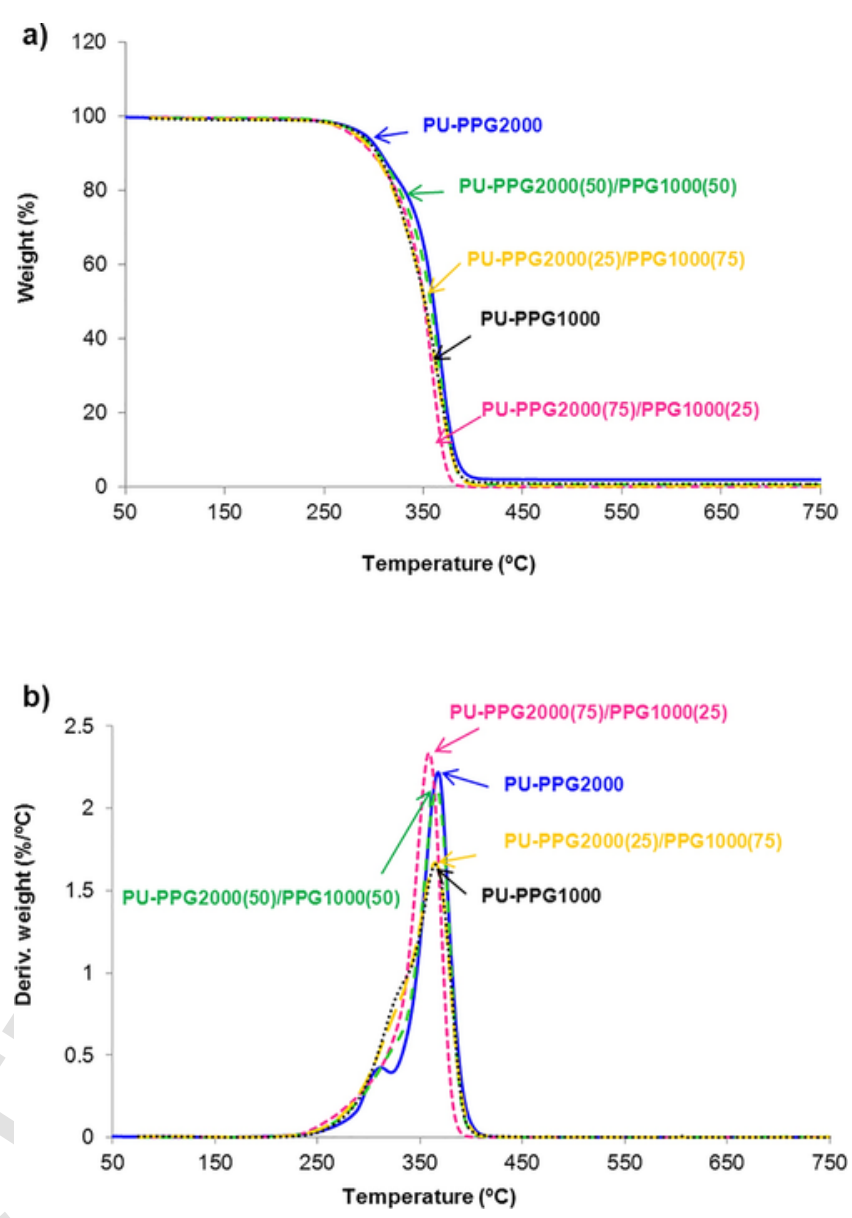

Fig. 7. Variation of (a) the weight and (b) the derivative of the weight as a function of the temperature for the thermoplastic PUs made with PPG1000, PPG200 and PPG2000 + PPG1000 mixtures.

Table 2a

Temperatures at which $5\left(\mathrm{~T}_{5 \%}\right)$ and $50\left(\mathrm{~T}_{50 \%}\right) \mathrm{wt} \%$ are lost, and temperature of maximum decomposition of the thermoplastic polyurethanes. TGA experiments.

\begin{tabular}{llll}
\hline PU & $\mathrm{T}_{5 \%}\left({ }^{\circ} \mathrm{C}\right)$ & $\mathrm{T}_{50 \%}\left({ }^{\circ} \mathrm{C}\right)$ & $\mathrm{T}_{\max }\left({ }^{\circ} \mathrm{C}\right)$ \\
\hline PU-PPG2000 & 291 & 360 & 368 \\
PU- & 278 & 351 & 359 \\
PPG2000(75)/PPG1000(25) & & & 365 \\
PU- & 286 & 357 & 365 \\
PPG2000(50)/PPG1000(50) & 282 & 351 & 365 \\
PU- & & & \\
PPG2000(25)/PPG1000(75) & 287 & 351 & \\
PU-PPG1000 & &
\end{tabular}

of linear viscoelasticity is more ample when the amount of PPG2000 in the polyurethane increases. Therefore, a strain of $2.5 \%$ is selected for studying the viscoelastic properties of the thermoplastic polyurethanes.

Table 2b

Temperatures and weight losses of the thermal decompositions of the thermoplastic polyurethanes. DTGA experiments.

\begin{tabular}{|c|c|c|c|c|c|}
\hline \multirow[t]{2}{*}{ PU } & \multicolumn{2}{|c|}{ First degradation } & \multicolumn{2}{|c|}{ Second degradation } & \multirow[t]{2}{*}{ Residue (wt\%) } \\
\hline & $\mathrm{T}_{1}\left({ }^{\circ} \mathrm{C}\right)$ & Weight $\operatorname{loss}_{1}(\mathrm{wt} \%)$ & $\mathrm{T}_{2}\left({ }^{\circ} \mathrm{C}\right)$ & Weight $\operatorname{loss}_{2}(w t \%)$ & \\
\hline PU-PPG2000 & 310 & 16 & 368 & 82 & 2 \\
\hline PU-PPG2000(75)/PPG1000(25) & 311 & 16 & 359 & 84 & 0 \\
\hline PU-PPG2000(50)/PPG1000(50) & 326 & 23 & 365 & 76 & 1 \\
\hline PU-PPG2000(25)/PPG1000(75) & 326 & 26 & 365 & 73 & 1 \\
\hline PU-PPG1000 & 329 & 35 & 365 & 63 & 2 \\
\hline
\end{tabular}



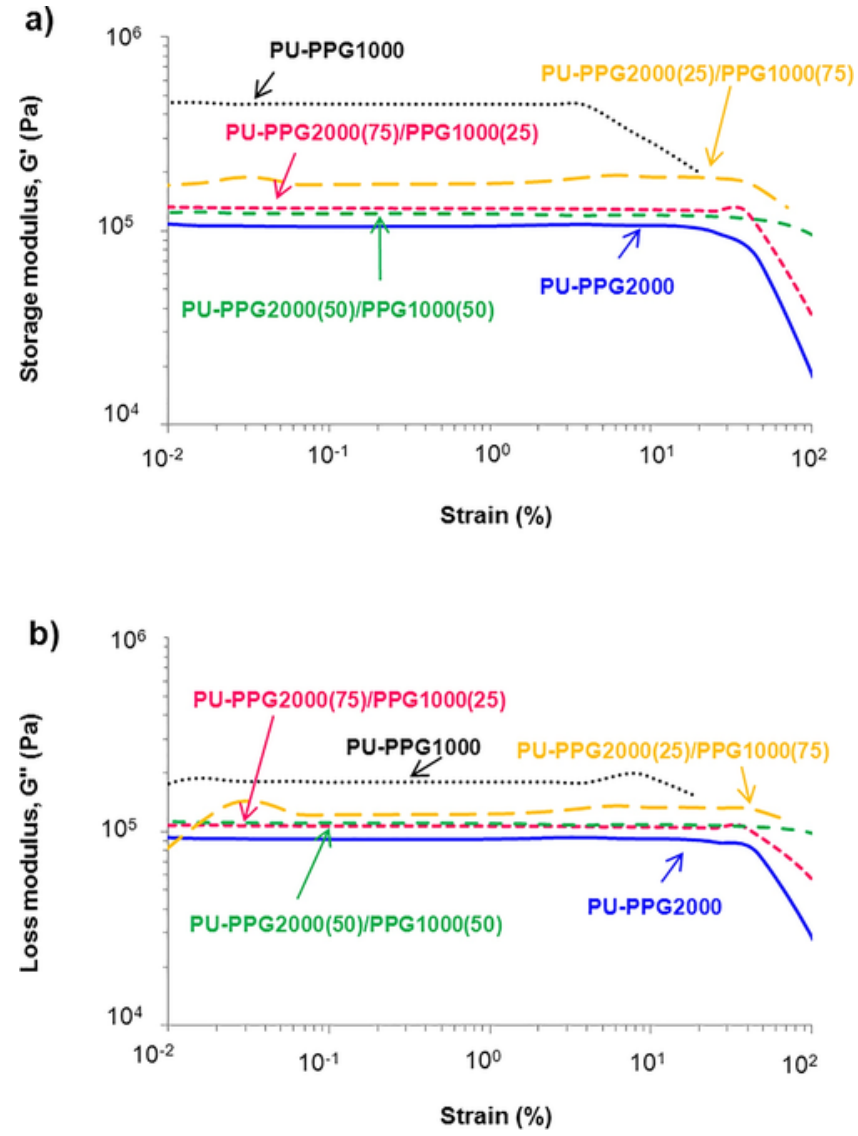

Fig. 8. Variation of the (a) storage $(G)$ and (b) loss $(G)$ moduli as a function of the strain for the thermoplastic PUs. T: $25^{\circ} \mathrm{C}$; frequency: $1 \mathrm{~Hz}$. Plate-plate rheology experiments (amplitude sweep).

Fig. 9a shows the variation of the storage modulus as a function of the frequency for the thermoplastic PUs; strain amplitude of $2.5 \%$ was used. The lowest storage modulus corresponds to PU-PPG2000 and there is an increase of the storage modulus by increasing the PPG1000 content. Interestingly, as compared to PU-PPG1000, the addition of $25 \mathrm{wt} \%$ PPG2000 decreases noticeably the storage modulus of the polyurethane, likely due to higher degree of phase separation, in agreement with TGA results. On the other hand, the rheological behavior of all PUs made with PPG1000 + PPG2000 mixtures is somewhat similar between them and to that of PU-PPG2000, indicating the dominance of the longer polyol chains on the viscoelastic behavior of these polyurethanes. Furthermore, at $25{ }^{\circ} \mathrm{C}$ and frequency of $100 \mathrm{~s}^{-1}$, the storage moduli of all polyurethanes are lower than $3 \times 10^{5} \mathrm{~Pa}$ (PU-PPG1000 is an exception), anticipating that they follow Dahlquist criterion [24].

All thermoplastic PUs show a cross-over between the storage and loss moduli. Fig. 9b shows, as typical example, the variation of the storage and loss moduli at $25^{\circ} \mathrm{C}$ as a function of the frequency for PU-PPG2000(50)/PPG1000(50). At frequency below $4.4 \mathrm{rad} \mathrm{s}^{-1}, \mathrm{G}$ is smaller than $G$ indicating that the viscous rheological behavior is dominant, and at frequency above $4.4 \mathrm{rad} \mathrm{s}^{-1}, \mathrm{G}$ is higher than $\mathrm{G}$ and the elastic rheological behavior is dominant. Table 3 shows the values of modulus and frequency at the cross-over of the storage and loss moduli for the polyurethanes. According to Table 3, the modulus at the cross-over of the PU increases by increasing the PPG1000 content. In general, the frequency at the cross-over of the polyurethanes decreases by increasing their PPG1000 content, PU-PPG2000(50)/PPG1000(50) polyurethane is an exception (the frequency at the cross-over is similar
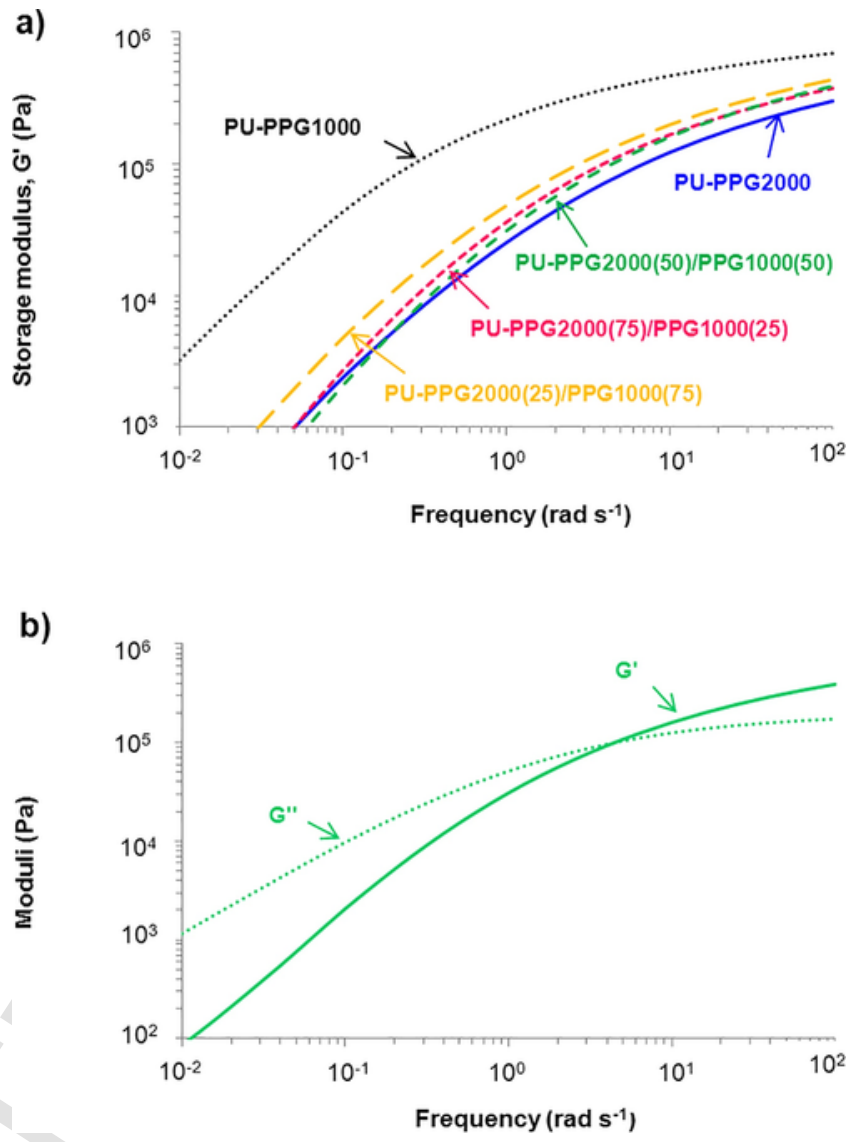

Fig. 9. (a) Variation of the storage modulus $(G)$ as a function of the frequency for the thermoplastic PUs. (b) Variation of the storage and loss moduli as a function of the frequency for PU-PPG2000(50)/PPG1000(50). T: $25^{\circ} \mathrm{C}$; Strain: $2.5 \%$. Plate-plate rheology experiments (frequency sweep).

Table 3

Values of frequency ( $\left.\omega_{\text {cross-over }}\right)$ and modulus $\left(G_{\text {cross-over }}\right)$ at the cross-over of the storage and loss moduli, and values of relaxation time $\left(t_{R}\right)$ of the thermoplastic polyurethanes. Plate-plate rheology experiments (frequency sweep).

\begin{tabular}{|c|c|c|c|}
\hline PU & $\begin{array}{l}\mathrm{G}_{\text {cross-over }} \\
(\mathrm{Pa})\end{array}$ & $\begin{array}{l}\omega_{\text {cross-over }}(\mathrm{rad} \\
\left.\mathrm{s}^{-1}\right)\end{array}$ & $\begin{array}{l}t_{\mathrm{R}} \\
(\mathrm{s})\end{array}$ \\
\hline PU-PPG2000 & $7.5 \cdot 10^{4}$ & 4.25 & 0.23 \\
\hline $\begin{array}{l}\text { PU- } \\
\text { PPG2000(75)/PPG1000(25) }\end{array}$ & $8.9 \cdot 10^{4}$ & 3.27 & 0.31 \\
\hline $\begin{array}{l}\text { PU- } \\
\text { PPG2000(50)/PPG1000(50) }\end{array}$ & $9.9 \cdot 10^{4}$ & 4.41 & 0.23 \\
\hline $\begin{array}{l}\text { PU- } \\
\text { PPG2000(25)/PPG1000(75) }\end{array}$ & $9.6 \cdot 10^{4}$ & 2.59 & 0.38 \\
\hline PU-PPG1000 & $1.2 \cdot 10^{5}$ & 0.34 & 2.91 \\
\hline
\end{tabular}

to that for PU-PPG2000). On the other hand, the relaxation time $\left(t_{\mathrm{R}}\right)$ at $25{ }^{\circ} \mathrm{C}$ of the polyurethanes $\left(t_{\mathrm{R}}\right)$ is the inverse of the frequency at the cross-over ( $\omega_{\text {cross-over }}$ ) increases by increasing the PPG1000 content (Table 3). The higher relaxation time of PU-PPG1000 is related to its low degree of phase separation, and all other polyurethanes show much lower and similar relaxation times, in agreement with their higher degree of phase separation.

In this study, Chanǵs viscoelastic window [25] was employed to predict the pressure sensitive adhesion property of the thermoplastic PUs. In order to obtain Changs viscoelastic window of the polyurethanes at $25{ }^{\circ} \mathrm{C}$, the values of $\mathrm{G}$ and $\mathrm{G}$ at frequencies of 0.01 and $100 \mathrm{rad} \cdot \mathrm{s}^{-1}$ were obtained from Fig. 9a and $G$ values were plotted versus $G$ ones. Fig. 10 shows Changs viscoelastic windows of the ther- 


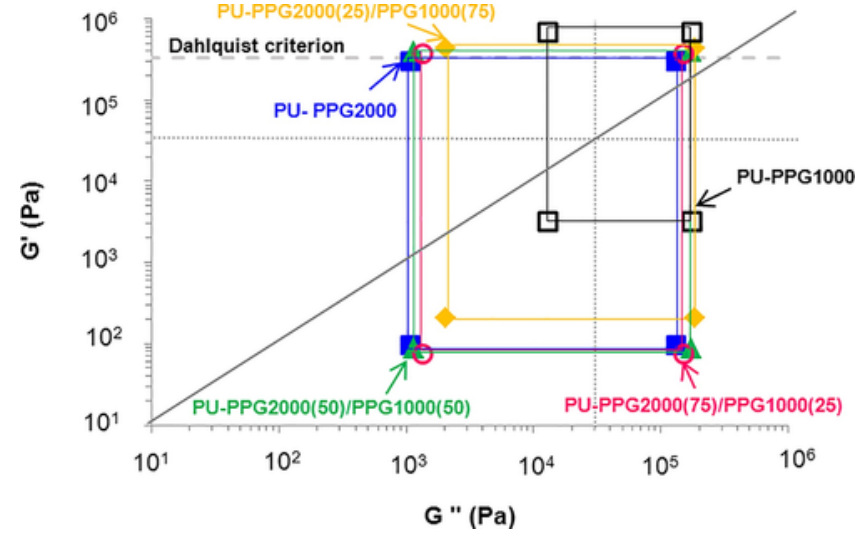

Fig. 10. Changs viscoelastic windows at $25{ }^{\circ} \mathrm{C}$ for the thermoplastic PUs made with PPG1000, PPG2000 and PPG2000 + PPG1000 mixtures. Doted lines indicated the four regions of Changs viscoelastic window. Solid line corresponds to $G=G(\tan$ delta $=1)$. Dashed line indicates Dahlquist criterion.

moplastic PUs and all them, except PU-PPG1000, can be considered general purpose or removable PSAs because of the squares are located in the center and slightly shifted to the bottom left quadrant, i.e, the region with lower values of $G$ and $G$. All polyurethanes, except PU-PPG100, show similar Chanǵs viscoelastic windows. On the other hand, all thermoplastic PUs have values of $\mathrm{G}$ below $3 \cdot 10^{5} \mathrm{~Pa}$ indicating that they follow Dahlquist criterion ( $\mathrm{G}^{\prime}<3.3 \cdot 10^{5} \mathrm{~Pa}$ ) [24]; however, the value of $\mathrm{G}$ at $100 \mathrm{rad} \cdot \mathrm{s}^{-1}$ of PU-PPG1000 is $6.9 \cdot 10^{5} \mathrm{~Pa}$ that is above Dahlquist criterion, and this polyurethane wont show pressure sensitive adhesion property at $25{ }^{\circ} \mathrm{C}$.

The viscoelastic properties of the polyurethanes were also studied by temperature sweep plate-plate rheology experiments. Fig. 11 shows the variation of the storage modulus $(G)$ as a function of the temperature. The highest storage moduli correspond to PU-PPG1000, PU-PPG2000(25)/PPG1000(75) and PU-PPG2000(75)/PPG1000(25), and they are very similar, the storage modulus of PU-PPG2000(50)/ PPG1000(50) is lower than expected. At low temperature PU-PPG2000, PU-PPG2000(50)/PPG1000(50) and PU-PPG2000(75)/PPG1000(25) have $\mathrm{G}$ values below $3 \cdot 3 \cdot 10^{5} \mathrm{~Pa}$ and, therefore, they may show pressure sensitive adhesion property at temperatures below $25{ }^{\circ} \mathrm{C}$. On the other hand, all polyurethanes show a cross-over of the storage and loss moduli. The values of temperature and modulus at the cross-over of the storage and loss moduli of the polyurethanes are given in Table 4. All polyurethanes show similar modulus at the cross-over and the temperatures at the cross-over are always lower than $35^{\circ} \mathrm{C}$. In general, the temperature at the cross-over increases by increasing the PPG1000 con-

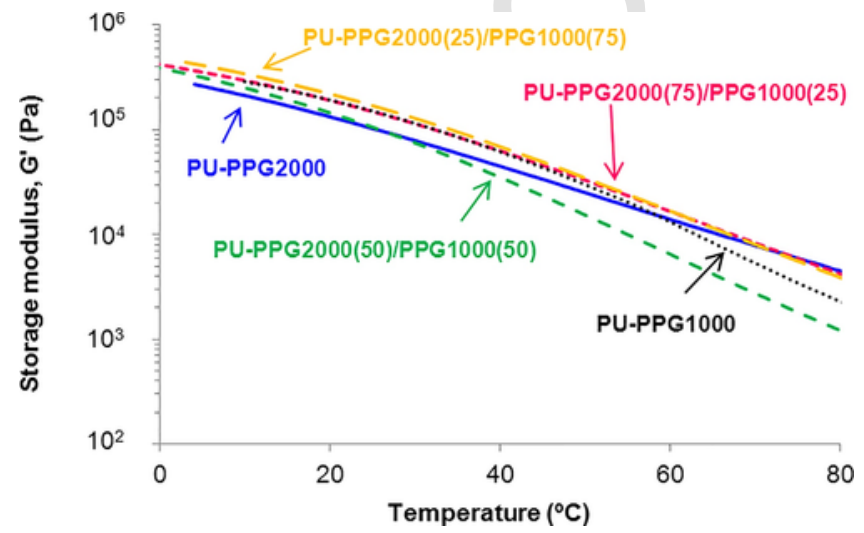

Fig. 11. Variation of the storage modulus $(G)$ as a function of the temperature for the thermoplastic PUs.
Table 4

Values of temperature and modulus at the cross-over of the storage and loss moduli of the thermoplastic polyurethanes. Plate-plate rheology experiments (temperature sweep).

\begin{tabular}{lll}
\hline PU & $\mathrm{T}_{\text {cross-over }}\left({ }^{\circ} \mathrm{C}\right)$ & $\mathrm{G}_{\text {cross-over }}(\mathrm{Pa})$ \\
\hline PU-PPG2000 & 27 & $8.8 \cdot 10^{4}$ \\
PU-PPG2000(75)/PPG1000(25) & 32 & $1.0 \cdot 10^{5}$ \\
PU-PPG2000(50)/PPG1000(50) & 26 & $9.9 \cdot 10^{4}$ \\
PU-PPG2000(25)/PPG1000(75) & 35 & $1.0 \cdot 10^{5}$ \\
PU-PPG1000 & 35 & $8.1 \cdot 10^{4}$ \\
\hline
\end{tabular}

tent of the polyurethanes likely due to lower degree of phase separation; however, the temperature at the cross-over is lower than expected in PU-PPG2000(50)/PPG1000(50). Considering that below the cross-over temperature, the elastic behavior of the polyurethanes is dominant and above that temperature the viscous behavior is dominant, the thermoplastic PUs may exhibit tack at temperatures above and below room temperature.

\subsection{Adhesion properties of thermoplastic PUs}

The viscoelastic properties play an important role in the adhesion properties of pressure sensitive adhesives. Chu [26] showed that the storage moduli at low frequency $\left(0.1 \mathrm{rad} \cdot \mathrm{s}^{-1}\right)$ and at high frequency (100 rad $\cdot \mathrm{s}^{-1}$ ) were both relevant and necessary for predicting pressure sensitive adhesion performance of rubber-resin blends. On the other hand, for obtaining an optimum balance of peel, tack and shear properties in silicone PSAs, G at frequency of $0.1 \mathrm{rad} \cdot \mathrm{s}^{-1}$ should be lower than $400 \mathrm{~Pa}$, and $\mathrm{G}\left(100 \mathrm{rad} \cdot \mathrm{s}^{-1}\right) / \mathrm{G}\left(0.1 \mathrm{rad} \cdot \mathrm{s}^{-1}\right)$ should be between 5 and 300 [27]. According to Fig. $9 \mathrm{a}$, at $25{ }^{\circ} \mathrm{C}$ the values of $\mathrm{G}$ at $0.01 \mathrm{rad} \cdot \mathrm{s}^{-1}$ for the thermoplastic PUs are between 0.008 and 350 Pa (PU-PPG1000 has much higher $G$ value at $0.01 \mathrm{rad} \cdot \mathrm{s}^{-1}$ ), anticipating good tack at room temperature. On the other hand, the bonding of PSAs is favoured for low value of $\mathrm{G}$ at $0.1 \mathrm{rad} \cdot \mathrm{s}^{-1}$ and the debonding of PSAs is favoured for high values of $G$ and $G$ at $100 \mathrm{rad} \cdot \mathrm{s}^{-1}$ [28]. Therefore, it can anticipated that the bonding of thermoplastic PUs will be favoured when PPG 2000 content increases ( $\mathrm{G}$ at $0.1 \mathrm{rad} \cdot \mathrm{s}^{-1}$ ) and the debonding will be favoured in PU-PPG1000, i.e., good cohesion but low peel strength can be expected.

Stress-strain curves at $25{ }^{\circ} \mathrm{C}$ of the thermoplastic PU coatings on stainless steel plate are given in Fig. 12 and they show the absence of fibrillation because of it is cleanly detached from the steel probe [29]. The tack was taken at the maximum of the strain-stress curves, and similar high tack is obtained in the PU coatings made with $50 \mathrm{wt} \%$ or more PPG2000 in which higher degree of phase separation is obtained and in which less content of associated urethane is found.

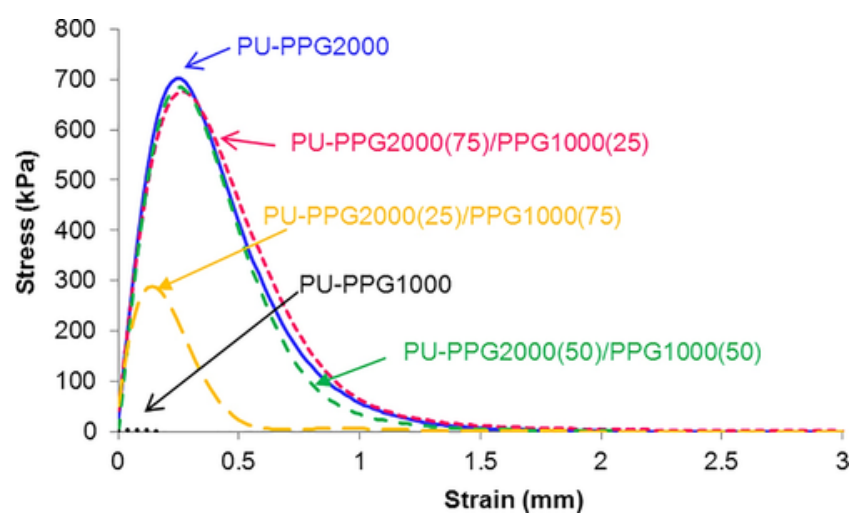

Fig. 12. Variation of the stress as a function of the strain for PU coatings on stainless steel plate. T: $25^{\circ} \mathrm{C}$. 
Because of the temperature at the cross-over of the storage and loss moduli determined by temperature sweep plate-plate rheology experiments ranges between 26 and $35{ }^{\circ} \mathrm{C}$ (Table 4), the PU coatings may exhibit tack at temperatures above and below room temperature, and therefore, the tack was also measured at temperatures below and above $25{ }^{\circ} \mathrm{C}$. According to Fig. 13, because of the lower degree of phase separation and important contribution of associated urethanes, PU-PPG1000 coating does not show tack at any temperature. PU-PPG2000 shows high tack that is slightly higher at $10^{\circ} \mathrm{C}$ than at 25 and $37^{\circ} \mathrm{C}$, and this can be ascribed to higher degree of phase separation, low $\mathrm{T}_{\mathrm{g}}$ value $\left(-51{ }^{\circ} \mathrm{C}\right)$ and temperature at the cross-over of the moduli at $27^{\circ} \mathrm{C}$. The PU coating made with $75 \mathrm{wt} \%$ of PPG 2000 shows high similar tack than PU-PPG2000 at 10 and $25{ }^{\circ} \mathrm{C}$ and it is slightly higher at $37{ }^{\circ} \mathrm{C}$, because its structure is dominated by the PPG2000 soft domains and the temperature at the cross-over of the moduli is $32{ }^{\circ} \mathrm{C}$. The PU coating made with $50 \mathrm{wt} \%$ of PPG2000 shows high similar tack at 25 and $37^{\circ} \mathrm{C}$ but lower tack at $10{ }^{\circ} \mathrm{C}$ than PU-PPG2000 and PU-PPG2000(75)/ PPG100(25) because of the value of $\mathrm{T}_{\mathrm{g}}$ is $-41{ }^{\circ} \mathrm{C}$. Finally, the PU coating made with $25 \mathrm{wt} \%$ of PPG2000 shows tack at 25 and $37{ }^{\circ} \mathrm{C}$ but not at $10^{\circ} \mathrm{C}$ because of its important contribution of PPG1000 soft domains and bonded urethane groups.

Finally, Fig. 14 shows the $180^{\circ}$ peel strength values of aluminum 5754/PU coating/PET film joints for the polyurethanes. $180^{\circ}$ peel strength values of joints made with PU coatings prepared with $50 \mathrm{wt} \%$ or more PPG2000 are low, having values between 2 and $4 \mathrm{~N} / \mathrm{cm}$, which are typical of removable PSAs [30]; however, the joints fail cohesively in the PU coating. These PU coatings show excellent tack in broader range of temperature (Fig. 13). Therefore, further studies should be carried out for improving the cohesion of the PU coatings.

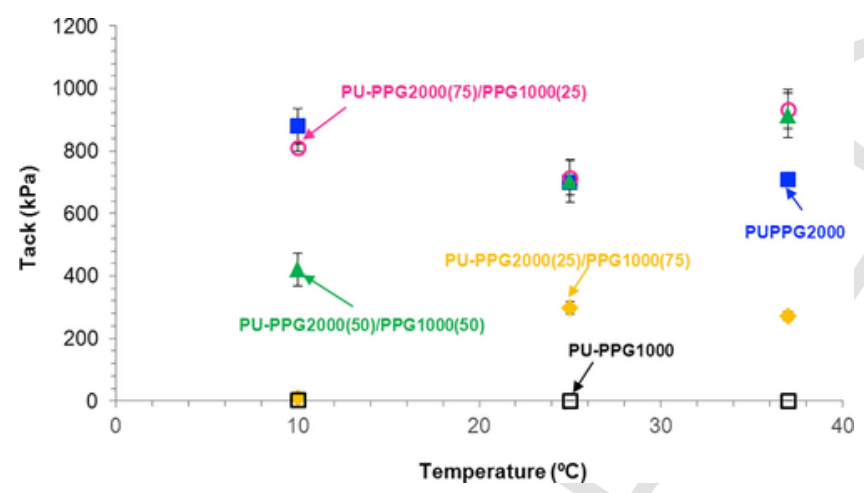

Fig. 13. Variation of the tack of PU coatings on stainless steel plate as a function of the temperature.

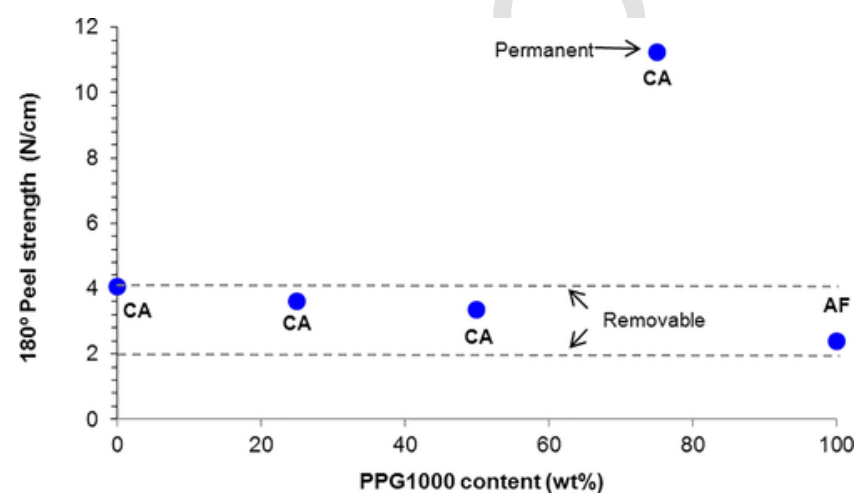

Fig. 14. Variation of the $180^{\circ}$ peel strength values of aluminum 5754/PU coating/PET film joints as a function of PPG1000 content in the PU coating. Locus of failure: CA = cohesive failure of the PU coating; $\mathrm{AF}=$ adhesion failure to aluminum.
On the other hand, the joint made with PU-PPG2000(25)/PPG1000(75) shows higher $180^{\circ}$ peel strength and an adhesion failure to aluminum; unfortunately, this PU coating shows limited tack at $25^{\circ} \mathrm{C}$ (Fig. 13).

\section{Conclusions}

Thermoplastic PU coatings with good tack at $10-37{ }^{\circ} \mathrm{C}$ can be prepared by using PPG2000 + PPG1000 mixtures containing $50 \mathrm{wt} \%$ or more PPG2000. The structure of the thermoplastic polyurethanes made with $50 \mathrm{wt} \%$ or more PPG2000 were dominated by the soft domains of PPG2000 with minor content of bonded urethane and important degree of phase separation. Furthermore, these polyurethanes followed Dahlquist criterion, they showed $\mathrm{T}_{\mathrm{g}}$ values lower than $-40{ }^{\circ} \mathrm{C}$, and they had a temperature of the cross-over of moduli at $26-32{ }^{\circ} \mathrm{C}$; as a consequence, PU coatings made with $50 \mathrm{wt} \%$ or more PPG2000 had good tack and low $180^{\circ}$ peel strength, and they had good potential as removable PSAs. PU coating made with $25 \mathrm{wt} \%$ PPG2000 and $75 \mathrm{wt} \%$ PPG1000 showed lower degree of phase separation and important content of associated urethane, they had low $\mathrm{T}_{\mathrm{g}}$ value and the temperature of the cross-over of moduli is $35^{\circ} \mathrm{C}$, so it had potential as high shear PSA. However, PU-PPG1000 did not show pressure sensitive adhesion property.

\section{Acknowledgments}

Authors thanks IfarmaPyc S.L. Company (Albacete, Spain) for financial support.

\section{References}

[1] I. Benedek, M.M. Feldstein (Eds.), Handbook of Pressure Sensitive Adhesive and Products: Applications of Pressure-Sensitive Products, CRC, Taylor \& Francis, Boca Raton (Fl), London (MN), New York (NY), 2009, pp. 1-92, (Chap. 4).

[2] Handbook of Pressure Sensitive Adhesive and Products: Technology of Pressure-Sensitive Adhesives and Products, In: I. Benedek, M.M. Feldstein (Eds.), Chap. 11, CRC, Taylor \& Francis, Boca Raton (Fl), London (MN), New York (NY), 2009, pp. 1-21.

[3] M. Lagiewczyk, Z. Czech, Polyurethane pressure-sensitive adhesives as raw materials for the manufacturing of protective films, Pol. J. Chem. Technol. 13 (2011) 47-50.

[4] M. Lagiewczyk, Z. Czech, Water-dispersible polyurethane systems used as pressure-sensitive adhesives, Polymery 51 (2006) 456-459.

[5] K. Asada, K. Fukano, K. Yamashita, E. Nakamishi, Improved heat and solvent resistance of pressure-sensitive adhesives thermally processable by isocyanate dimer dissociation, J. Appl. Polym. Sci. 132 (2015) 41444, https://doi.org/10.1002/app. 41444.

[6] Z. Czech, R. Milker, A. Malec, Crosslinking of PUR-PSA water-borne systems, Rev. Adv. Mater. Sci. 12 (2006) 189-199.

[7] A.K. Singh, D.S. Mehra, U.K. Niyogi, S. Sabharwal, R.K. Khandal, Effect of tackifier and crosslinkers on electron beam curable polyurethane pressure sensitive adhesive, Radiat. Phys. Chem. 81 (2012) 547-552.

[8] I. Yilgör, E. Yilgör, G.L. Wilkes, Critical parameters in designing segmented polyurethane and their effect on morphology and properties: a comprehensive review, Polymer 58 (2015) A1-A36.

[9] R. Dahl, Polyurethane-based pressure-sensitive adhesives, US Patent 3,437,622, 1969 (assigned to Anchor Continental).

[10] L. Tushaus, Pressure-sensitive adhesives based on cyclic terpene urethane resin. US Patent 3,718,712 A, 1971 (assigned to Minnesota Mining and Manufacturing Company).

[11] L.W. Mobley, V.R. Hofmeister, Removable polyurethane adhesives, US Patent 5,227,409, 1993 (assigned to Dow Chemical Company).

[12] R.B. Orr, Pressure-sensitive adhesive formulation comprising underindexed isocyanate to active hydrogen composition, US Patent 5,157,101 A, 1992 (assigned to Norwood Industries).

[13] Y. Nakamura, S. Nakano, K. Ito, K. Imamura, S. Fujii, M. Sasaki, Y. Urahama, Adhesion properties of polyurethane pressure-sensitive adhesive, J. Adh. Sci. Tech. 27 (2013) 263-277.

[14] A. Baron, J. Rodriguez-Hernandez, E. Ibarboure, C. Derail, E. Papon, Adhesives based on polyurethane graft multiblock copolymers: tack, rheology and first morphological analyses, Int. J. Adhes. Adhes. 29 (2009) 1-8. 
[15] N. Akram, R.S. Gurney, M. Zuber, M. Ishaq, J.L. Keddie, Influence of polyol molecular weight and type on the tack and peel properties of waterborne polyurethane pressure-sensitive adhesives, Macromol. React. Eng. 7 (2013) 493-503.

[16] A. Lopez, E. Degrandi, E. Canetta, J.L. Keddie, C. Creton, J.M. Asua, Simultaneous free radical and addition miniemulsion polymerization: effect of the diol on the microstructure of polyurethane-acrylic pressure-sensitive adhesives, Polymer 52 (2011) 3021-3030.

[17] A. Lopez, Y. Reyes, E. Degradi - Contraires, E. Canetta, C. Creton, J.M. Asua, Simul taneous free radical and addition miniemulsion polymerization: effect of the chain transfer agent on the microstructure of polyurethane-acrylic pressure-sensitive adhesives, Macromol. Mater. Eng. 298 (2013) 53-66.

[18] E. Degrandi-Contraires, A. Lopez, Y. Reyes, J.M. Asua, C. Creton, High-shear-strength waterborne polyurethane/acrylic soft adhesives, Macromol. Mater. Eng. 298 (2013) 612-623.

[19] E. Degrandi-Contraires, R. Udagama, E. Bourgeat-Lami, T.F.L. Mckenna, K. Ouzineb, C. Creton, Mechanical properties of adhesive films obtained from PU-acrylic hybrid particles, Macromolecules 44 (2011) 2643-2652.

[20] V.W. Srichatrapimuk, S.L. Cooper, Infrared thermal analysis of polyurethane block polymers, J. Macromol. Sci. B. 15 (1978) 267-311.

[21] A.G. Strikovsky, V.V. Zharkov, Infra-red spectroscopy study of equilibrium association of urethane groups in poly(ether urethane)s, Polymer 34 (1993) 3397-3401.

[22] J. Mattia, P.A. Painter, Comparison of hydrogen bonding and order in a polyurethane and poly(urethane- urea) and their blends with poly(ether glycol), Macromolecules 40 (2007) 1546-1554.
[23] M. Fuensanta, J.A. Jofre-Reche, F. Rodríguez-Llansola, V. Costa, J.I. Iglesias, J.M. Martín-Martínez, Structural characterization of polyurethane ureas and waterborne polyurethane urea dispersions made with mixtures of polyester polyol and polycarbonate diol, Prog. Org. Coat. 112 (2017) 141-152.

[24] C.A. Dahlquist, Handbook of Pressure-Sensitive Adhesives Technology, in: D. Satas (Ed.), Warckwick, 1999, pp. 121-138.

[25] E.P. Chang, Viscoelastic windows of pressure-sensitive adhesives, J. Adhes. 34 (1991) 189-200.

[26] S.G. Chu, Dynamic mechanical properties of pressure-sensitive adhesives, in: L.H. Lee (Ed.), Adhesive Bonding, Plenum Press, New York, 1991, pp. 97-138.

[27] K.Y. Ho, K. Dodou, Rheological studies on pressure-sensitive silicone adhesives and drug-in-adhesive layers as a means to characterize adhesive performance, Int. J. Pharm. 333 (2007) 24-33.

[28] A.J. Kinloch, J.G. Williams, The mechanics of peel test, in: D.A. Dillard, A.V. Pocius (Eds.), Adhesion Science and Engineering: The Mechanics of Adhesion, Elsevier Science BV, Amsterdam, 2002, pp. 273-302.

[29] F. Deplace, C. Carelli, S. Mariot, H. Retsos, A. Chateauminois, K. Ouzineb, C. Creton, Fine tuning the adhesive properties of a soft nanostructures adhesive with rheological measurements, J. Adhes. 85 (2009) 18-54.

[30] Z. Czech, Synthesis of removable and repositionable water-borne pressure-sensitive adhesive acrylics, J. Appl. Polym. Sci. 9 (2003) 886-892. 